\title{
Influence of seeing a red face during the male-male encounters of mosquito-specialist spiders
}

\author{
Fiona R. Cross ${ }^{1,2,3}$ (D) $\cdot$ Robert R. Jackson ${ }^{1,2} \cdot$ Lisa A. Taylor ${ }^{3}$ \\ Published online: 23 January 2020 \\ (C) The Psychonomic Society, Inc. 2020
}

\begin{abstract}
Males of Evarcha culicivora, an East African jumping spider (Salticidae), have bright red faces. Here, we investigated how seeing a red face might influence a male's behaviour during encounters with another male. We applied black eyeliner to conceal the red on a male's face and measured the spectral properties of male faces with and without the eyeliner. Only the faces without eyeliner reflected in the long-wavelength range corresponding to red. In experiments over 2 days, where eyeliner was absent on the first day and present on the second, we compared how two groups of males responded to their mirror images. Face Group: eyeliner concealed their faces. Head Group: eyeliner was applied to the tops of the males' heads instead of on their faces. The males from both groups displayed to their mirror image as if it were a living same-sex conspecific. However, when they could see a red face, males in the face group escalated to higher levels of aggression to their mirror image and initiated displaying from farther away than when the red had been concealed. We also found that the influence of eyeliner was stronger for the face group than for the head group. These findings suggest that, when seeing a red face, E. culicivora males become more confident that the individual in view is another male.
\end{abstract}

Keywords Aggression $\cdot$ Decision-making $\cdot$ Perception $\cdot$ Salticidae $\cdot$ Vision

For many reasons, we can thank Prof. Stephen Lea for the insights his research has given us into how animals categorize different stimuli (e.g., Lea \& Wills, 2008), including stimuli that may be found in nature (e.g., Lea, Poser-Richet, \& Meier, 2015). Indeed, animals with good eyesight often have to identify and discriminate between many different objects, individuals, and categories (Burge, 2010; Palmer, 1999; Tinbergen, 1951). Besides needing to discern specific features of different objects and individuals (Cronin, Johnsen, Marshall, \& Warrant, 2014; Palmer, 1999; Treisman, 1998), animals sometimes need to attend to multiple features from a single sensory modality as well as features from more than one modality (e.g., vision and olfaction). Multimodal and multicomponent

Fiona R. Cross

fiona.r.cross@gmail.com

1 International Centre of Insect Physiology and Ecology, Thomas Odhiambo Campus, P.O. Box 30, Mbita Point, Kenya

2 School of Biological Sciences, University of Canterbury, Private Bag 4800, Christchurch, New Zealand

3 Entomology and Nematology Department, University of Florida, P.O. Box 110620, Gainesville, FL 32611-0620, USA cues (Candolin, 2003; Partan, 2017) may, for instance, assist with identifying another individual as being a member of the same species, as well as assist with further classifying of individuals (e.g., female versus male and immature versus mature).

We have been interested in how the colour red might function as a salient feature in conspecific rival identification by a jumping spider (family Salticidae). With more than 6,000 described species (Maddison, 2015; Prószyński, 2017), this spider family is a major group of vision-proficient predators and, owing to their unique, complex eyes (Harland, Li, \& Jackson, 2012; Warrant \& McIntyre, 1993), salticids see with spatial acuity considerably better than that known for any other animals of comparable size (Land \& Nilsson, 2012). Besides having exceptional spatial acuity, salticids also use colour as cues for making decisions in contexts that include classifying prey (Raška, Štys, \& Exnerová, 2017; Taylor, Maier, Byrne, Amin, \& Morehouse, 2014b), identifying landmarks (Hoefler \& Jakob, 2006) and, especially, courtship and threat displays (e.g., Taylor \& McGraw, 2013).

Salticids have eight eyes, but colour vision and vision requiring exceptional spatial acuity are achieved primarily by a large forward-facing pair called the 'principal eyes' (Homann, 1928; Land \& Nilsson, 2012). Colour vision inclusive of 
green and ultraviolet may be universal among salticids. However, the mechanisms by which colour vision is achieved may vary considerably, and the extent to which different species might rely on colour vision inclusive of red has been of particular interest (Blest, Hardie, McIntyre, \& Williams, 1981; DeVoe, 1975; Outomuro et al., 2019; Yamashita \& Tateda, 1976; Zurek et al., 2015).

For the salticid we investigate here, Evarcha culicivora, red may be particularly relevant in two contexts. This species, from the Lake Victoria region of East Africa, specializes at feeding on vertebrate blood by actively selecting as preferred prey blood-carrying mosquitoes (Jackson, Nelson, \& Sune, 2005). After feeding on blood, a mosquito's abdomen becomes noticeably red; this suggests that, for E. culicivora, seeing a red abdomen might be an important step toward identifying its preferred prey. We are currently investigating this possibility. However, our objective here is to consider, instead, how red might function for this species in the context of intraspecific interactions. The adult males, but not the juveniles or the adult females, of E. culicivora have bright-red faces and, during intraspecific interactions, individuals typically face each other while adopting species-specific postures and movement patterns that we call 'displays'. These displays differ depending on whether males are interacting with females or with other males (Cross, Jackson, \& Pollard, 2008) and, as only the males have bright-red faces, seeing a red face may serve as evidence that the other individual is an E. culicivora male.

Here, we investigate whether seeing a red face influences a male's decision to initiate an interaction with another male, as well as his subsequent decisions to escalate or desist. In our experiments, however, the other male is the salticid's own reflection in a mirror. This method ('mirror testing') is based on knowing that salticids respond to their own mirror images in much the same way as they respond to living, same-sex rivals (e.g., Forster, 1982). This means we can ascertain a spider's decision to escalate or desist without the decisions of a living rival introducing confounding variables (see Briffa \& Sneddon, 2007). Mirror testing has frequently been used before in studies on salticid behaviour; previous objectives have included determining capacities for identifying rivals at different distances, under different ambient light levels and under different ambient spectral conditions (e.g., Cerveira, Jackson, \& Nelson, 2019; Harland, Jackson, \& Macnab, 1999; Jackson \& Blest, 1982; Lim \& Li, 2006), but not for investigating the influence of specific features of the virtual rival.

\section{Method}

\section{General}

The test spiders in our experiments were adult males of $E$. culicivora collected from our field site (see Cross et al.,
2008) in western Kenya 2-3 weeks before use. Basic methods for maintaining and handling test spiders were as in earlier studies (for details, see Cross \& Jackson, 2014).

\section{Colour manipulation}

Our definition of 'face' is the spider's clypeus (i.e., the portion of the spider's carapace below the principal-eye corneas) as well as the area around the margins of the principal eye corneas. In experiments, the entire area of red on the male's face (see Fig. 1a) was either concealed or left exposed, with concealment being achieved using a black liquid eyeliner (Urban Decay Cosmetics, Costa Mesa, CA; colour: 'Perversion'; see Fig. 1b). We chose this black eyeliner because it closely matched the colour of the spider's underlying cuticle and because it had been used before to effectively manipulate the colour patterns of other salticid species without negatively affecting the spiders' behaviour (e.g., see Taylor, Clark, \& McGraw, 2014a; Taylor \& McGraw, 2013). Evarcha culicivora males from the field vary substantially in body size (body length 3-7 mm; Cross, Jackson, \& Pollard, 2007), but we standardized size in our experiments by using only larger males $(6.0-7.0 \mathrm{~mm}$, accurate to the nearest $\mathrm{mm})$, as larger males offered greater ease of applying the eyeliner.

After we used enough $\mathrm{CO}_{2}$ to gently immobilize the spider (repeating if necessary), we placed it under a dissecting microscope and used a fine brush to apply the eyeliner, taking care to avoid contacting its eyes. For concealing a spider's red face, we covered the clypeus with the eyeliner. We also applied eyeliner to another group of males, but not where it would conceal the red face; instead, a similar amount of eyeliner was applied to an area of similar size above and behind the spider's principal-eye corneas (i.e., on the dorsal surface of the spider's 'head'). Although the test spiders in this group retained their red faces, having eyeliner applied to another part of the head meant that they experienced a procedure that was much the same as what was experienced by test spiders with concealed faces. Each spider was immediately fed after the eyeliner application. We analyzed the spectral properties of our colour manipulation for male faces (see Fig. 1c), but we only collected the spectral data for each male when his red face was either exposed or concealed, never both, and these males were not used in our experiments on mirror testing.

\section{Mirror testing}

We conducted our mirror experiments between $0900 \mathrm{~h}$ and $1300 \mathrm{~h}$ (laboratory photoperiod 12L:12D, lights on at 0700 hours). Each spider was tested twice and, because the eyeliner was permanent after application, each male was first tested without any eyeliner (Day 1) and then, on the following day (Day 2), he was retested after having eyeliner applied. There were two groups of test spiders, defined by where the eyeliner 

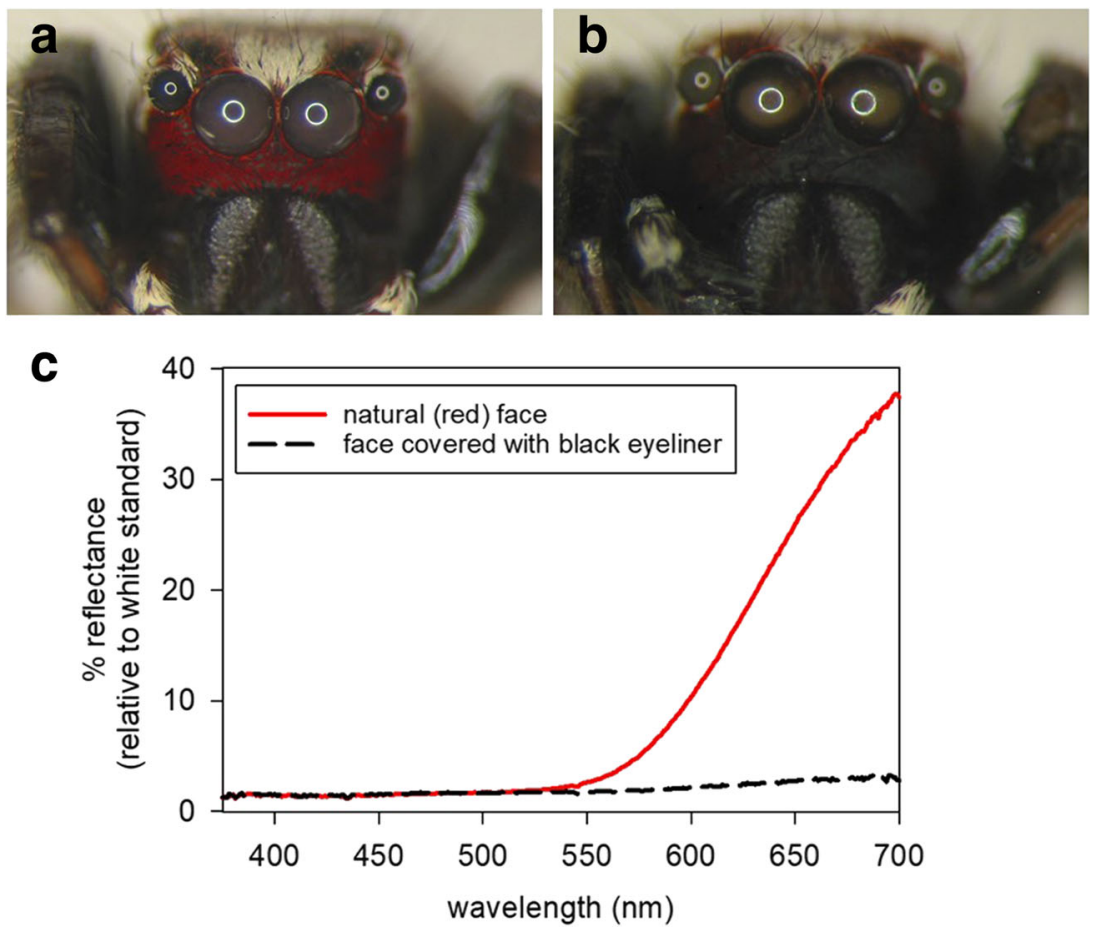

Fig. 1 Experimental colour manipulation of male Evarcha culicivora faces. a Males' red faces exposed. b Red on males' faces concealed by applying black liquid eyeliner. c Mean reflectance spectra for a subset of males with red left exposed $(N=7)$ and males with eyeliner on their faces $(N=4)$. Spectral properties were obtained using a custom-built microspectrophotometer that could collect precise data within a circular sampling area of $0.4 \mathrm{~mm}$ in diameter. This consisted of a standard spectrophotometer (USB2000, Ocean Optics, Dunedin, FL, USA) coupled to a modified Leica DMLB2 fluorescence light microscope fitted with a $\times 40$ quartz objective lens (Leica Microsystems, Wetzlar, Germany) and illuminated with a full-spectrum Leica $75 \mathrm{~W}$ xenon arc lamp (Leica

was applied on Day 2. Face group: eyeliner covered the clypeus, entirely concealing the red coloration. Head group: eyeliner covered the top of the carapace, leaving the male's red facial coloration exposed. Each spider was fed to satiation on the day before Day 1. After the trial on Day 1, eyeliner was applied, and then the test spider was fed to satiation again. No individual was used as a test spider in more than one pair of trials.

The testing arena (see Fig. 2a) was a transparent Perspex box (140 mm long $\times 110 \mathrm{~mm}$ wide $\times 20 \mathrm{~mm}$ high) with a mirror (length $110 \mathrm{~mm}$, height $20 \mathrm{~mm}$ ) at one end and with a removable glass top. The inside of the arena was lined with white nylon mosquito netting (mesh diameter $2 \mathrm{~mm}$ ). This netting was sewn into a rectangular pouch $(140 \times 115 \times 20$ $\mathrm{mm}$; see Fig. 2b) which, when fitted over a rectangular wire frame $(130 \times 110 \times 20 \mathrm{~mm}$; wire thickness $1.5 \mathrm{~mm})$, was held taut inside the arena. The longer sides of the netting pouch were sewn shut, but the narrow sides of the pouch were open, with one of these open ends facing the mirror, and with the other end, on the opposite side, serving as opening through which the test spider could be introduced on to the netting
Microsystems, Wetzlar, Germany). Reflectance measures, taken in a dark room, were relative to a Spectralon diffuse reflectance white standard (Labsphere, Inc., North Sutton, NH, USA). Unfortunately, the optics of the microscope cut out a portion of the UV spectrum and so this instrument only provides data within the range of 375-700 nm. However, by using a standard UV-VIS spectrophotometer, we qualitatively confirmed that E. culicivora males do not have any peaks of UV reflectance on their red face. Each male was measured twice and, using the mean value for each male, we then determined the mean value for the two different groups. (Colour figure online)

inside the arena. These were the same netting pouches used in an earlier study (Cross, 2016) for testing E. culicivora's response to silk draglines. We decided to use these pouches again here because they made observations easier; while inside the pouches, test spiders were less easily distracted by people moving in the vicinity.

Before testing began, the test spider was transferred from its maintenance cage to a 40-mm-long glass tube (diameter 10 $\mathrm{mm}$, stopper in each end of the tube) and kept there for a 5-min pretrial period, after which one of the stoppers was removed and the end piece of the arena farthest from the mirror was raised to provide access to the open end of the netting pouch. From the open end of the tube, the test spider was then introduced into the pouch inside the arena, after which the end piece of the arena was returned so as to keep the test spider inside. Test spiders usually walked spontaneously out of the tube and into the arena within $5 \mathrm{~min}$; however, if this did not happen, then the other stopper was removed, and, using a soft brush, the spider was lightly prodded, whereupon it promptly moved into the arena. We aborted testing whenever the test spider entered the arena by running, instead of walking, out of 


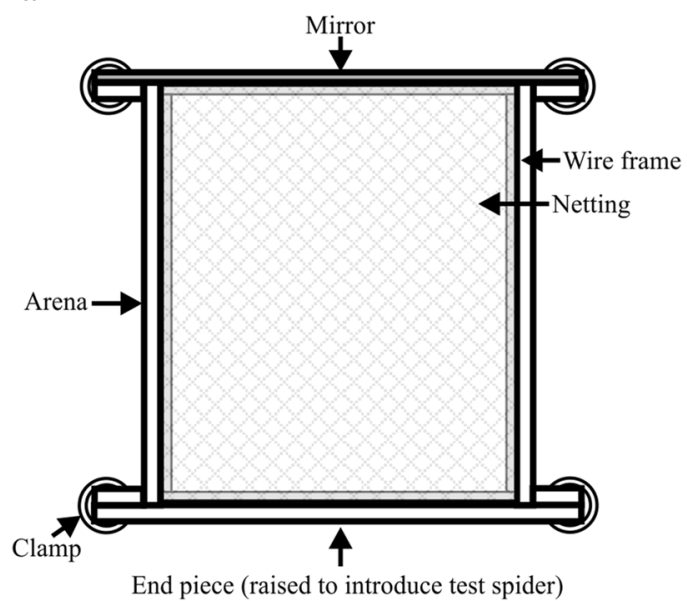

b

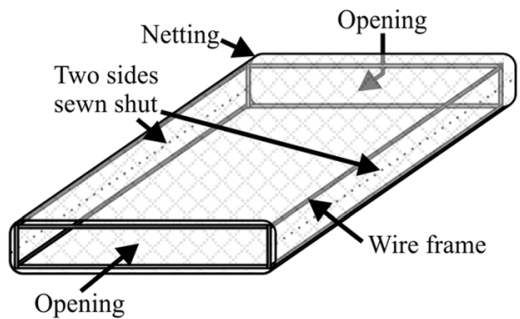

b Closer view of netting on wire frame. To begin trial, end piece furthest from mirror was raised, and the test spider stepped out of a holding tube (not shown) and onto the netting inside the arena

highest level reached before the test spider retreated and failed to return was recorded as a rank (see Dugatkin \& Reeve, 1998), with this envisaged as indicating the level of risk a spider is willing to accept in a given contest (Rank 1 being the lowest and Rank 3 being the highest).

Rank 1 (posturing from a distance): While facing a rival, the male positions his forelegs, chelicerae, and abdomen in specific, distinctive ways, sometimes accompanied by a distinctive walking pattern. Legs are typically in a hunched or an arched posture and, intermittently, the male sways, flicks one or both of his forelegs up and down, or waves his pedipalps from side to side.

Rank 2 (propulsive displays): The spider rapidly closes the distance between himself and his rival by lunging or leaping.

Rank 3 (face-to-face contact): With his forelegs extending out to the side and fangs usually extended, the spider pushes the front of his cephalothorax against the other spider.

\section{Data analysis}

On Day 1, test spiders from both groups were free of eyeliner. On Day 2, eyeliner was present, but situated differently depending on the group (face group, red on face concealed; head group, red on face exposed). We looked for evidence of red influencing response to a virtual rival by first determining the 'rank score' for each male. This score was the rank recorded on Day 1 minus the rank recorded on Day 2, which meant that a male's score was positive if rank was higher when eyeliner was absent than when it was present. In the same way, we calculated and compared scores for interaction duration, display latency, first-display distance, and closest distance. We considered negative as well as positive scores to ensure that we did not miss any unforeseen influences of the eyeliner on test spider behaviour. 
As the distributions of scores did not meet the prerequisites for parametric data analysis, we used nonparametric statistics (see Howell, 2002). For each group, we considered whether the presence of eyeliner influenced male response by using Wilcoxon matched-pairs tests (null hypothesis: score $=0$ ). To determine whether using eyeliner to conceal the red on a male's face had a stronger effect than putting eyeliner on his head (leaving red exposed on his face), we used Mann-Whitney $U$ tests to compare the scores for the face group with scores for the head group. As these comparisons meant that some data sets were analysed twice, we applied an adjusted alpha of 0.025 .

\section{Results}

Test spiders in the face group had rank scores significantly larger than zero (Wilcoxon: $Z=3.52, p<.001$; see Fig. 3a); the ranks reached were higher (i.e., the spiders were more aggressive) when their red faces were exposed (Day 1) compared with when their red faces were concealed (Day 2). However, the rank scores of test spiders in the head group (red faces exposed on Day 1 and Day 2) were not significantly different from zero (Wilcoxon: $Z=0.71, p=.478$; see Fig. $3 b$ ). We also found that rank scores for the face group were significantly larger than rank scores for the head group (MannWhitney: $Z=2.47, p=.013$ ), indicating a stronger effect on behaviour when eyeliner was applied to a male's face instead of a male's head.

The distance at which males in the face group began displaying (first distance) to their mirror image on Day 1 (red face exposed) was significantly greater than on Day 2 (red face concealed; Wilcoxon: $Z=2.73, p=.006$; see Fig. $4 a)$. By contrast, first-distance scores for males in the head group were not significantly different from zero (Wilcoxon: $Z=0.83, p=.409$; see Fig. 4b). Although our data suggested that first-distance scores for the face group were larger than first-distance scores for the head group, this difference was not significant (Mann-Whitney: $Z=1.84, p=.066$ ).

None of the other scores we considered were significantly different from zero. Wilcoxon matched-pairs tests: Interaction duration scores (face group: $Z=1.49, p=.136$; head group: $Z$ $=0.62, p=.538$ ), display latency scores (face group: $Z=0.78$, $p=.436$; head group: $Z=0.63, p=.525)$, closest-distance scores (face group: $Z=1.48, p=.140$; head group: $Z=0.88, p$ $=.379)$. Mann-Whitney $U$ tests: interaction duration scores $(Z$ $=1.20, p=.232)$, display latency scores $(Z=0.80, p=.421)$, closest-distance scores $(Z=0.53, p=.597)$.

\section{Discussion}

Our spectral data indicate that the faces of E. culicivora males strongly reflect in the long-wavelength range corresponding to red. In experiments we found that, when this red coloration was concealed with black eyeliner, males still interacted with their mirror images, but they were less inclined to escalate conflict. These findings are relevant in the context of colour vision, but there is still much we need to learn about how colour-related stimuli influence $E$. culicivora's responses. We have evidence that $E$. culicivora males attend to red as a relevant feature, but we have not yet determined whether, for example, it is specifically brightness, chroma, or hue that matters. We also have not yet determined whether there are other colours on the male's body, including parts that might reflect $\mathrm{UV}$, which could influence interactions between $E$. culicivora males.

This is not the first research in which mirrors were used for testing the way E. culicivora males respond to virtual rivals (Cross, 2016; Cross \& Jackson, 2009, 2014). However, in the earlier work, mirrors were used for investigating whether individuals escalate the level of aggression they express over access to resources such as a potential mate or preferred prey. Here, our objective was different because we were primarily interested in whether a particular visual feature (i.e., a red face) influenced the decisions made by males during encounters with other males.

Perhaps the most celebrated example of red on the body of a rival eliciting an aggressive response comes from experiments on the three-spined stickleback (Gasterosteus aculeatus) during the time of classic ethology. Niko Tinbergen (1951) in particular emphasized that stickleback males are strongly predisposed to respond with threat displays specifically when they see a red belly on a rival, with other stimuli originating from the rival seeming to be largely ignored. For example, the 'rivals' used during experiments were often dummies made from wood or from a dead fish of the same or another species, and yet, even when the dummy only crudely resembled another stickleback male, the living stickleback male still responded aggressively as long as red was visible on the rival's belly. In basic respects, our findings for $E$. culicivora males resemble the findings for the sticklebacks because, again, a particular colour and the location of this colour mattered (red on the face for the spider; red on the belly for the fish), but whether this similarity runs much deeper is less clear.

For Tinbergen and his colleagues, including Konrad Lorenz, the stickleback experiments and many similar experiments with other animals illustrated something especially important. These authors emphasized that the potential information animal sensory systems can deliver may be vast, but animals often attend to only a very small portion of available stimuli when they are in situations where prompt, adaptive responding is needed. Tinbergen's preferred term for these highly specific subsets of potentially available information was 'sign stimuli' (Tinbergen, 1951), whereas Lorenz (1950) more often used the term 'releaser'. 
a

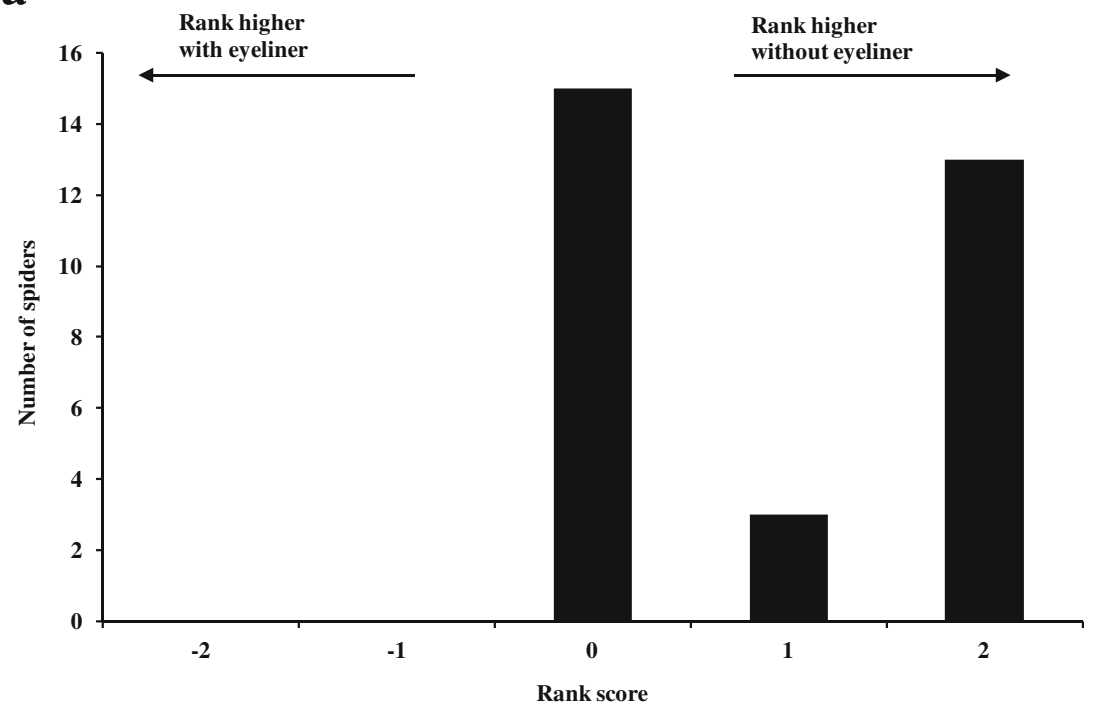

b

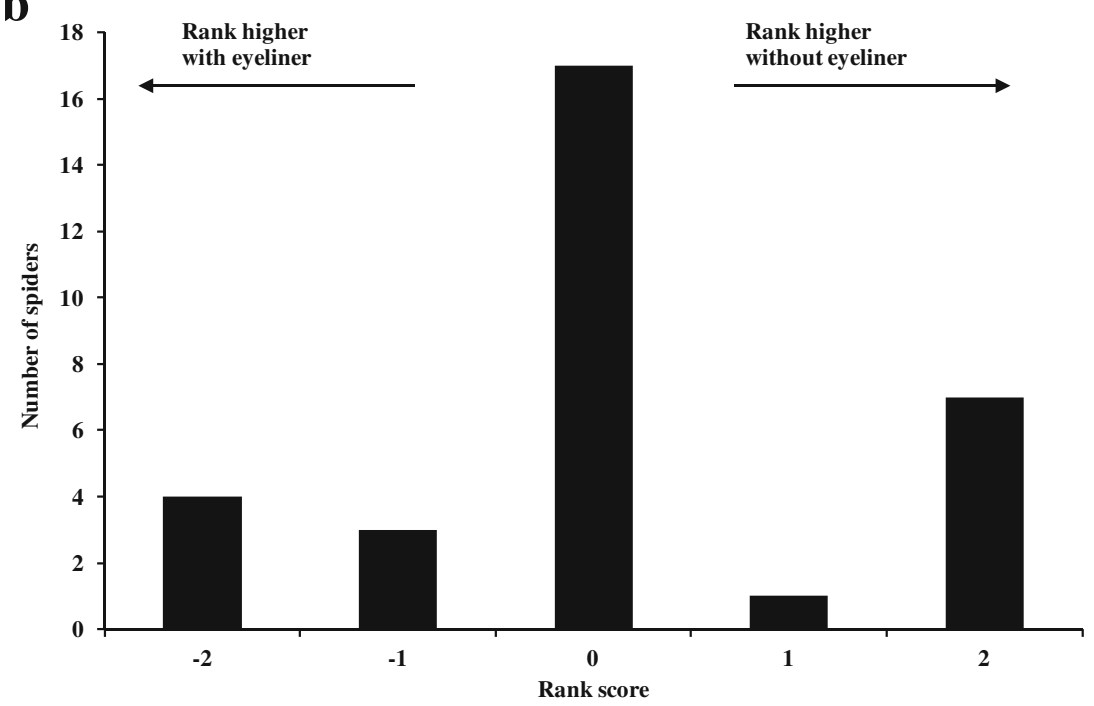

Fig. 3 Rank scores attained by males of Evarcha culicivora: rank attained on Day 1 (no eyeliner present) minus rank attained on Day 2 (eyeliner present; see text for details). a Black eyeliner on spider's face concealing

red (face group; $N=31$ ). b Black eyeliner on top of spider's head, leaving red on face exposed (head group; $N=32$ )

The expression 'sign stimulus' has potential for being a convenient way of saying that a particular stimulus normally accompanies the presence of something specific (i.e., it is a 'sign' of something specific). If this was all that 'sign stimulus' meant, then we might say that a red face is a sign stimulus for E. culicivora males (i.e., it is a sign that another spider is a rival male). However, the emphasis Tinbergen put on animals responding to a sign stimulus while largely ignoring other available stimuli has been shown to be problematic even in the case of stickleback males (e.g., Rowland, 1982) and, for this and other reasons, Tinbergen's expression 'sign stimulus' is no longer so widely used.

Likewise, for E. culicivora, 'ignoring other available stimuli' is not what we found. What we found instead is that, regardless of whether E. culicivora males saw a red face or face covered with eyeliner, they responded by displaying in much the same way as they normally displayed during encounters with living same-sex conspecific individuals (Cross et al., 2008). We conclude from this that, for identifying another individual as a conspecific male, it was not essential for E. culicivora to see a red face. It seems more appropriate to propose that a red face was, for E. culicivora, information that was used in the context of deciding what to do, but this was not simply all that mattered.

When considering how seeing a red face affects $E$. culicivora, Lorenz's expression 'releaser' feels even more out of place. Lorenz went further than Tinbergen by proposing a model for how behaviour is often orchestrated, with 
$\mathbf{a}$

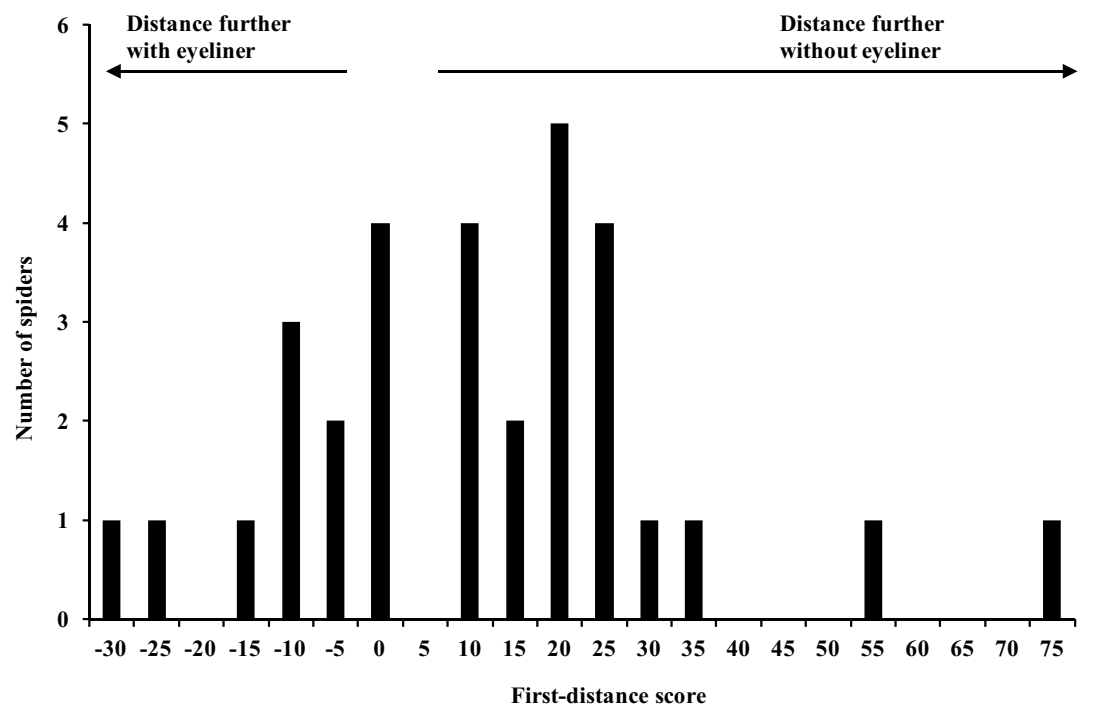

b

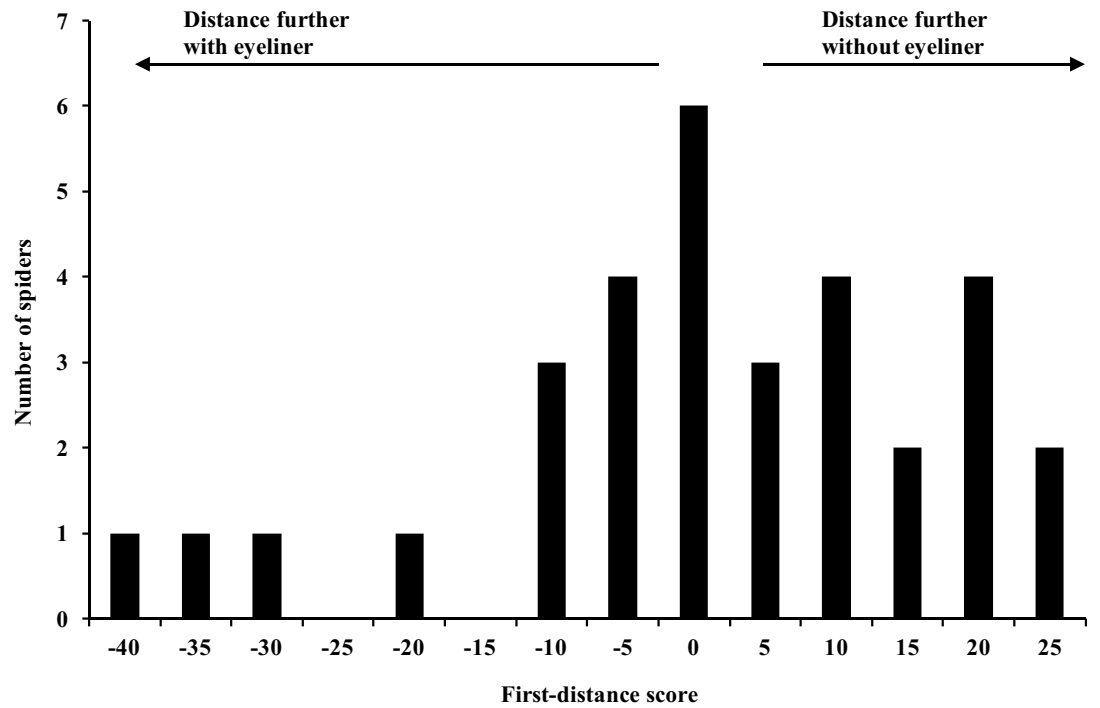

Fig. 4 First-distance scores attained by males of Evarcha culicivora: distance spider was from the mirror when he first displayed on Day 1 (no eyeliner present) minus distance spider was from the mirror when he first displayed on Day 2 (eyeliner present; see text for details). a Black

releasers being analogous to a finger pushing a 'button' (i.e., an innate releasing mechanism, which is envisaged as a component of the animal's nervous system) and with pushing the right button 'releasing' the animal's fixed action pattern (Lorenz, 1950). In our study, when males in the face group were tested with a virtual rival that had a red face on one day and with a rival that had a concealed red face on the next day, there were significant effects on rank scores and distance scores; test spiders initiated displaying from further away and they adopted higher levels of aggression (rank) when they could see a red face. In fact, no test spiders adopted higher levels of aggression when red was concealed instead of eyeliner on spider's face concealing red (face group; $N=31$ ). b Black eyeliner top of spider's head, leaving red on face exposed (head group; $N$ $=32$ )

exposed (see Fig. 3a). We see this as evidence that face colour mattered to E. culicivora males, but it was not as though seeing red acted in a way that was analogous to simply pushing the right button for releasing a male's threat displays.

There was another factor that covaried with face colour; the trial with no eyeliner (red face exposed) was always on Day 1, and the trial with eyeliner concealing red was always on Day 2. It might be argued that the experience of applying the eyeliner had affected how a test spider responded to seeing a rival, but our findings for the head group are contrary to this alternative hypothesis. The spiders in this group had red exposed on both days and, despite having eyeliner applied to the top of 
their heads on Day 2, all of their scores were nonsignificant (i.e., not distinguishable from zero). Moreover, the rank scores for the face group were significantly higher than the rank scores for the head group, suggesting that it was specifically the appearance of the spiders' faces, rather than the procedure of applying the eyeliner, that affected test-spider response.

We still might discuss our findings in the context of $E$. culicivora males identifying another individual as being a conspecific same-sex rival, only now with identification ('recognition') not being envisaged as an all-or-none phenomenon but rather pertaining to E. culicivora males having varying levels of confidence in the identifications they make. A similar perspective can be seen in a series of ingenious experiments in which males of another salticid species, Lyssomanes viridis, were presented with images of conspecific and heterospecific salticid individuals (Tedore \& Johnsen, 2013). Some of these images were composites in which the facial coloration and morphology of one species was combined with the leg coloration of another salticid species. These males more often displayed at a male or a female composite image when this image was presented in conjunction with silk. Tedore and Johnsen (2013) proposed that, for L. viridis, there is a threshold for identifying a conspecific individual and that contact with the silk contributes to crossing this threshold.

Our experiments were different because, instead of adding another variable (silk present or absent), we manipulated a specific visual feature (red) and found apparent effects on test-spider motivation. Our experiments can be called 'mirror testing', with the spider in the mirror being a virtual rival. However, the expression 'mirror testing' is better known in a different context-namely, experiments in which the objective is to determine capacity for self-recognition (Reiss \& Morrison, 2018). Interest in this can be traced back to experiments in which chimpanzees, after having experience of looking in a mirror, then had conspicuous paint markings applied to their faces. These chimpanzees showed no overt response to the markings in the absence of mirrors, but, when tested again with mirrors, their behaviour was as expected for individuals seeing themselves instead of another chimpanzee; they stared at the mirrors and then, instead of reaching out and touching the mirrors, they repeatedly touched the marking on their own faces (see Gallup, 1970). This work generated a lot of interest and there is now a large literature based on similar mirror testing for self-recognition using chimpanzees, other apes, and other animals (see Reiss \& Morrison, 2017).

Yet there are important differences between our mirror experiments and the self-recognition mirror experiments. For example, instead of adding a conspicuous marking, we hid the conspicuous red on the males' faces. The most important difference, however, may be that, in our experiments, each $E$. culicivora male was tested only twice. By contrast, before having a marking applied to their faces, animals in selfrecognition experiments usually encounter mirrors repeatedly and, initially, they respond to the mirror as though they have encountered a rival. By this criterion alone, our experiments are not self-recognition experiments. Another consideration is that our test spiders, while facing a mirror, never used their appendages to touch the eyeliner on their faces or heads. Instead, the spiders were busy making threat displays.

Acknowledgements We thank Stephen Abok Aluoch for his assistance in Kenya, and we thank David Clark for allowing us to use his microspectrophotometer to quantify our color manipulations. Maeve Cross provided valuable assistance with making the netting pouches. We also thank ICIPE and the National Museums of Kenya for assistance and support, which made this work possible. Our research was supported by grants from the Royal Society of New Zealand (Marsden Fund [UOC1301]), the National Geographic Society $(8676-09,6705-00)$, and the National Science Foundation (IOS-1557867).

Open practices statement The data for this study are available from the corresponding author upon request.

\section{References}

Blest, A. D., Hardie, R. C., McIntyre, P., \& Williams, D. S. (1981). The spectral sensitivities of identified receptors and the function of retinal tiering in the principal eyes of a jumping spider. Journal of Comparative Physiology, 145, 227-239. doi:https://doi.org/10. 1007/BF00605035

Briffa, M., \& Sneddon, L. U. (2007). Physiological constraints on contest behaviour. Functional Ecology, 21, 627-637. doi:https://doi.org/10. $1111 / \mathrm{j} .1365-2435.2006 .01188 . x$

Burge, T. (2010). Origins of objectivity. New York, NY: Oxford University Press.

Candolin, U. (2003). The use of multiple cues in mate choice. Biological Reviews, 78, 575-595. doi:https://doi.org/10.1017/ S1464793103006158

Cerveira, A. M., Jackson, R. R., \& Nelson, X. J. (2019). Dim-light vision in jumping spiders (Araneae, Salticidae): Identification of prey and rivals. Journal of Experimental Biology, 222, jeb198069. doi:https:// doi.org/10.1242/jeb.198069

Cronin, T. W., Johnsen, S., Marshall, N. J., \& Warrant, E. J. (2014). Visual ecology. Princeton, NJ: Princeton University Press.

Cross, F. R. (2016). Discrimination of draglines from potential mates by Evarcha culicivora, an East African jumping spider. New Zealand Journal of Zoology, 43, 84-95. doi:https://doi.org/10.1080/ 03014223.2015.1127262

Cross, F. R., \& Jackson, R. R. (2009). How cross-modality effects during intraspecific interactions of jumping spiders differ depending on whether a female-choice or mutual-choice mating system is adopted. Behavioural Processes, 80, 162-168. doi:https://doi.org/10.1016/j. beproc.2008.11.001

Cross, F. R., \& Jackson, R. R. (2014). Cross-modality effects of prey odour during the intraspecific interactions of a mosquito-specialist predator. Ethology, 120, 598-606. doi:https://doi.org/10.1111/eth. 12232

Cross, F. R., Jackson, R. R., \& Pollard, S. D. (2007). Male and female mate-choice decisions by Evarcha culicivora, an East African jumping spider. Ethology, 113, 901-908. doi:https://doi.org/10. 1111/j.1439-0310.2007.01394.x

Cross, F. R., Jackson, R. R., \& Pollard, S. D. (2008). Complex display behaviour of Evarcha culicivora, an East African mosquito-eating jumping spider. New Zealand Journal of Zoology, 35, 151-187. doi: https://doi.org/10.1080/03014220809510112 
DeVoe, R. D. (1975). Ultraviolet and green receptors in principal eyes of jumping spiders. The Journal of General Physiology, 66, 193-207. doi:https://doi.org/10.1085/jgp.66.2.193

Dugatkin, L. A., \& Reeve, H. K. (Eds.). (1998). Game theory and animal behavior. New York, NY: Oxford University Press.

Forster, L. M. (1982). Visual communication in jumping spiders (Salticidae). In P. N. Witt \& J. S. Rovner (Eds.), Spider communication: Mechanisms and ecological significance (pp. 161-212). Princeton, NJ: Princeton University Press.

Gallup, G. G., Jr. (1970). Chimpanzees: Self-recognition. Science, 167, 86-87. doi:https://doi.org/10.1126/science.167.3914.86

Harland, D. P., Jackson, R. R., \& Macnab, A. M. (1999). Distances at which jumping spiders (Araneae: Salticidae) distinguish between prey and conspecific rivals. Journal of Zoology, 247, 357-364. doi: https://doi.org/10.1111/j.1469-7998.1999.tb00998.x

Harland, D. P., Li, D., \& Jackson, R. R. (2012). How jumping spiders see the world. In O. Lazareva, T. Shimizu, \& E. A. Wasserman (Eds.), How animals see the world: Comparative behavior, biology, and evolution of vision (pp. 133-164). New York, NY: Oxford University Press.

Hoefler, C. D., \& Jakob, E. M. (2006). Jumping spiders in space: movement patterns, nest site fidelity and the use of beacons. Animal Behaviour, 71, 109-116. doi:https://doi.org/10.1016/j.anbehav. 2005.03.033

Homann, H. (1928). Beiträge zur Physiologie der Spinnenaugen: I. Untersuchungsmethoden. II. Das Sehvermögen der Salticiden [Contributions to the physiology of spider eyes: I. Examination methods. II. The eyesight of the salticids]. Zeitschrift für vergleichende Physiologie, 7, 201-268. doi:https://doi.org/10.1007/ BF00339163

Howell, D. C. (2002). Statistical methods for psychology (5th ed.). Belmont, CA: Wadsworth.

Jackson, R. R., \& Blest, A. D. (1982). The distances at which a primitive jumping spider, Portia fimbriata, makes visual discriminations. Journal of Experimental Biology, 97, 441-445.

Jackson, R. R., Nelson, X. J., \& Sune, G. O. (2005). A spider that feeds indirectly on vertebrate blood by choosing female mosquitoes as prey. Proceedings of the National Academy of Sciences (USA), 102, 15155-15160. doi:https://doi.org/10.1073/pnas.0507398102

Land, M. F., \& Nilsson, D.-E. (2012). Animal eyes (2nd ed.). Oxford, UK: Oxford University Press.

Lea, S. E. G., Poser-Richet, V., \& Meier, C. (2015). Pigeons can learn to make visual category discriminations using either low or high spatial frequency information. Behavioural Processes, 112, 81-87. doi: https://doi.org/10.1016/j.beproc.2014.11.012

Lea, S. E. G., \& Wills, A. J. (2008). Use of multiple dimensions in learned discriminations. Comparative Cognition \& Behavior Reviews, 3, 115-133. doi:https://doi.org/10.3819/ccbr.2008.30007

Lim, M. L. M., \& Li, D. (2006). Behavioural evidence of UV sensitivity in jumping spiders (Araneae: Salticidae). Journal of Comparative Physiology A, 192, 871-878. doi:https://doi.org/10.1007/s00359006-0126-5

Lorenz, K. Z. (1950). The comparative method in studying innate behavior patterns. Symposia of the Society for Experimental Biology, 4, 221-268.

Maddison, W. P. (2015). A phylogenetic classification of jumping spiders (Araneae: Salticidae). Journal of Arachnology, 43, 231-292. doi: https://doi.org/10.1636/arac-43-03-231-292

Outomuro, D., Zurek, D. B., Taylor, L. A., Cronin, T. W., Dharmaraaj, B., Kunte, K., \& Morehouse, N. I. (2019). The evolution of colour vision across jumping spiders. Integrative and Comparative Biology, 59, E176.

Palmer, S. E. (1999). Vision science: Photons to phenomenology. Cambridge, MA: MIT Press.

Partan, S. R. (2017). Multimodal shifts in noise: Switching channels to communicate through rapid environmental change. Animal Behaviour, 124, 325-337. doi:https://doi.org/10.1016/j.anbehav. 2016.08.003

Prószyński, J. (2017). Pragmatic classification of the world's Salticidae (Araneae). Ecologica Montenegrina, 12, 1-133.

Raška, J., Štys, P., \& Exnerová, A. (2017). How variation in prey aposematic signals affects avoidance learning, generalization and memory of a salticid spider. Animal Behaviour, 130, 107-117. doi:https://doi. org/10.1016/j.anbehav.2017.06.012

Reiss, D., \& Morrison, R. (2017). Reflecting on mirror self-recognition: A comparative view. In J. Call, G. M. Burghardt, I. M. Pepperberg, C. T. Snowdon, \& T. R. Zentall (Eds.), APA handbook of comparative psychology: Perception, learning, and cognition (pp. 745-763). Washington, DC: American Psychological Association.

Reiss, D., \& Morrison, R. (2018). Mirror self-recognition. In J. Vonk \& T. Shackelford (Eds.), Encyclopedia of animal cognition and behaviour. New York, NY: Springer. doi:https://doi.org/10.1007/ 978-3-319-47829-6 1493-1

Rowland, W. J. (1982). The effects of male nuptial coloration on stickleback aggression: A reexamination. Behaviour, 80, 118-126. doi: https://doi.org/10.1163/156853982X00481

Taylor, L. A., Clark, D. L., \& McGraw, K. J. (2014a). Natural variation in condition-dependent display colour does not predict male courtship success in a jumping spider. Animal Behaviour, 93, 267-278. doi: https://doi.org/10.1016/j.anbehav.2014.05.005

Taylor, L. A., \& McGraw, K. J. (2013). Male ornamental coloration improves courtship success in a jumping spider, but only in the sun. Behavioral Ecology, 24(4), 955-967. doi:https://doi.org/10. 1093/beheco/art011

Taylor, L. A., Maier, E. B., Byrne, K. J., Amin, Z., \& Morehouse, N. I. (2014b). Colour use by tiny predators: jumping spiders show colour biases during foraging. Animal Behaviour, 90, 149-157. doi:https:// doi.org/10.1016/j.anbehav.2014.01.025

Tedore, C., \& Johnsen, S. (2013). Pheromones exert top-down effects on visual recognition in the jumping spider Lyssomanes viridis. The Journal of Experimental Biology, 216, 1744-1756. doi:https://doi. org $/ 10.1242 / \mathrm{jeb} .071118$

Tinbergen, N. (1951). The study of instinct. Oxford, UK: Clarendon Press.

Treisman, A. (1998). Feature binding, attention and object perception. Philosophical Transactions of the Royal Society B, 353, 19980284. doi:https://doi.org/10.1098/rstb.1998.0284

Warrant, E. J., \& McIntyre, P. D. (1993). Arthropod eye design and the physical limits to spatial resolving power. Progress in Neurobiology, 40, 413-461. doi:https://doi.org/10.1016/0301-0082(93)90017-M

Yamashita, S., \& Tateda, H. (1976). Spectral sensitivities of jumping spider eyes. Journal of Comparative Physiology A, 105, 29-41. doi:https://doi.org/10.1007/BF01380051

Zurek, D. B., Cronin, T. W., Taylor, L. A., Byrne, K., Sullivan, M. L. G., \& Morehouse, N. I. (2015). Spectral filtering enables trichromatic vision in colorful jumping spiders. Current Biology, 25, R403-R404. doi:https://doi.org/10.1016/j.cub.2015.03.033

Publisher's note Springer Nature remains neutral with regard to jurisdictional claims in published maps and institutional affiliations. 